ISSN: $2594-4827$

\title{
O USO DO SCRATCH COMO FERRAMENTA PARA O ENSINO DE QUÍMICA ORGÂNICA
}

\author{
Cristiele de Freitas Pereira ${ }^{1}$ \\ Patrícia Tereza Souza da Luz ${ }^{2}$ \\ Solange Maria Vinagre Corrêa ${ }^{3}$ \\ Raimundo Negrão Neto ${ }^{4}$
}

\section{RESUMO}

A tecnologia vem adquirindo cada vez mais relevância no cenário educacional, pois vivemos em uma sociedade em constante transformação, na qual torna-se necessário buscar novos recursos para atingir as demandas dos alunos, alguns se prendem aos métodos tradicionais, porém grande parte cobra a inclusão de elementos tecnológicos com caráter didático. Este trabalho tem como objetivo relatar uma experiência da aplicação de um jogo para o ensino de Química Orgânica com docentes do ensino médio, no sentido de minimizar as dificuldades encontradas no processo de ensino. A validação do jogo ocorreu por meio de um questionário para 5 (cinco) docentes da área de química e possibilitou mensurar o grau de aceitação do jogo. Conclui-se que a união de jogos com os conteúdos de Química, como uma nova estratégia de ensino, poderá ser um caminho para um melhor desempenho escolar.

Palavras-chave: Recursos tecnológicos de ensino; Ensino de Química; Scratch.

\footnotetext{
${ }^{1}$ Mestranda pelo Programa de Pós-Graduação em Educação Profissional e Tecnológica, IFPA, Campus Belém. E-mail: crystiely.freitas@gmail.com.

${ }^{2}$ Docente do Programa de Pós-gradução em Educação Profissional e Tecnológica / IFPA, Campus Belém. E-mail:_patricia.luz@ifpa.edu.br

${ }^{3}$ Licenciada em Química pela Universidade Federal do Pará. Doutora em Educação pela Universidade Federal do Ceará. Docente Titular do Instituto Federal de Educação, Ciência e Tecnologia do Pará.

${ }^{4}$ Licenciado em química (2007). Mestre (2010) e Doutor (2014) em Química Orgânica pela Universidade Federal do Pará. Docente do Instituto Federal de Educação, Ciência e Tecnologia do Pará. E-mail: raimundo.neto@ifpa.edu.br
} 
ISSN: $2594-4827$

\title{
THE USE OF SCRATCH AS A TOOL FOR ORGANIC CHEMICAL TEACHING
}

\begin{abstract}
Technology has become increasingly relevant in the educational scenario, as we live in a society in constant transformation, in which it is necessary to seek new resources to meet the demands of students, some are tied to traditional methods, but much of it demands inclusion. of technological elements with didactic character. This paper aims to report an experience of applying a game for teaching Organic Chemistry with high school teachers, in order to minimize the difficulties encountered in the teaching process. The validation of the game took place through a questionnaire for 5 (five) chemistry teachers and made it possible to measure the degree of acceptance of the game. It is concluded that the union of games with Chemistry content, as a new teaching strategy, may be a way to better school performance.
\end{abstract}

KEYWORDS: Technological resources for teaching; Chemistry teaching; Scratch.

\section{INTRODUÇÃO}

Este artigo tem como objetivo relatar as experiências da aplicação de um jogo com docentes da área de química, que visava avaliar o grau de aceitação do jogo compreendido como experiência de produto educacional, e o que ele ainda precisava melhorar para ser um bom recurso didático para o ensino de química. O jogo foi elaborado na plataforma Scratch com o intuito de facilitar o entendimento sobre Química Orgânica, mais especificamente os conteúdos relacionados a "Funções Orgânicas", para os discentes e auxiliar os docentes para que tornem suas aulas mais atrativas.

Segundo Webbwer (2016), recentemente a plataforma Scratch vem ganhando espaço em projetos escolares pela flexibilidade e benefícios comprovados em diversas disciplinas como, por exemplo, em Nascimento e Costa (2017) que usaram a ferramenta Scratch para o ensino de química na construção de um jogo abordando o conteúdo de 
nomenclaturas dos hidrocarbonetos, e asseguram que o mesmo contribuiu para potencializar o ensino de nomenclatura dos hidrocarbonetos, bem como despertou o interesse dos alunos pelo assunto estudado. Já Cabral (2015), usou o Scratch para o ensino da matemática como ferramenta para o ensino e aprendizagem da geometria, observou que, com o uso do software os alunos se interessaram pelas atividades que foram propostas pelo professor e também colaboraram com os colegas, inclusive ensinando-os conceitos geométricos naturalmente.

A aprendizagem da Química passa necessariamente pela utilização de fórmulas, equações, símbolos, cálculos e uma série de representações que muitas vezes necessitam de um grau de abstração maior para sua compreensão. Por esse motivo, essa ciência é vista por muitos alunos como complexa de difícil aprendizado (SILVA FILHO, 2015).

Medeiros (2014) relata que essa dificuldade de aprender pode estar relacionada a forma como alguns professores repassam o conteúdo em sala de aula. Os modelos ainda são tradicionais, na qual o docente transmite o conhecimento químico através da memorização de fórmulas e equações.

Kleinubing (2016), afirma que, atualmente os resultados obtidos nas escolas que utilizam somente o método tradicional de ensino estão abaixo do esperado, isso porque os alunos são de uma geração muito mais familiarizada com aparatos tecnológicos e, portanto, acostumados com este meio e esperam que de alguma forma a escola se insira na era digital.

Diante de tais pressupostos, justifica-se a realização desta pesquisa no sentido de minimizar as dificuldades encontradas ao lecionar Química no atual contexto tecnológico e educacional, bem como fazer com que os docentes reflitam sobre o papel das tecnologias no ambiente de ensino como ferramenta mediadora para o processo de ensino aprendizagem.

Diante desta proposta, surgem alguns objetivos que norteiam esta pesquisa, o principal deles é auxiliar no processo de ensino aprendizagem da disciplina de Química no contexto das atuais transformações tecnológicas, re(conhecendo) as múltiplas possibilidades de aprendizagem e de interação que a tecnologia possa trazer para o ensino 
de um modo geral. Os específicos são: investigar se os docentes fazem ou já fizeram uso de jogos digitais em suas aulas; apresentar uma proposta de jogo, e verificar se os jogos digitais podem ser um bom recurso pedagógico para auxiliar o professor em suas aulas.

O texto está estruturado em três seções, a primeira compreende o referencial teórico, no qual é abordado o uso da ferramenta scratch para o processo de ensino aprendizagem, a segunda seção detalha o percurso metodológico do trabalho. A terceira seção apresenta os resultados e discussões.

\section{PLATAFORMA SCRATCH}

O Scratch é um software livre, desenvolvido pela Lifelong Kindergarten MIT Media Lab, no ano de 2003 e publicado em 2007. Ele permite a criação de histórias interativas, jogos e animações e o compartilhamento para a comunidade online. Desde 2013 o Scratch está disponível na forma online ou por meio do download gratuito para diversos sistemas operacionais. Ele já é utilizado em muitos países devido à rápida difusão pelo mundo e de ser oferecido em vários idiomas. Por se tratar de um software que não exige do usuário o conhecimento prévio sobre linguagem de programação, inicialmente foi indicado para jovens, mas atualmente é utilizado por todas as idades, pelo seu layout ser de fácil compreensão e utilização mínima de comandos (WEBBER et al, 2016).

Silva et al. (2016), defendem o uso dessa ferramenta alegando que esse software incentiva a criatividade e auxilia para a aprendizagem dos discentes. O Scratch é um software gratuito e que pode ser usado off-line como alternativa para auxiliar o docente em escolas que não possuem acesso a internet. Levando em consideração esses aspectos, o presente trabalho utilizou essa ferramenta para a criação de um jogo que aborda o conteúdo de funções orgânicas, o qual visa não apenas repassar conceitos químicos, mas mostrar de forma concreta como a disciplina de química está inserida diretamente em nossas vidas. Assim, mostrar para os alunos que a Química não é simplesmente um meio para a obtenção de médias anuais, mas que ela faz parte de nosso dia a dia. 


\section{PROCEDIMENTOS METODOLÓGICOS}

A presente pesquisa fundamentou-se numa perspectiva qualitativa, que é aquela não se preocupa com representatividade numérica, mas, sim, com o aprofundamento da compreensão de um grupo social, de uma organização, etc. (GERHARDT; SILVEIRA; 2009). Em outras palavras a pesquisa qualitativa é aquela que não se preocupa com o número de informações, mas com a qualidade das informações adquiridas durante a realização da pesquisa. A pesquisa divide-se em dois momentos, sendo eles:

I. Primeiro momento: Realizou-se investigações sobre aplicação de jogos que utilizaram a ferramenta scratch para o ensino de química, leituras sobre a temática. A revisão bibliografica permitiu delimitar as abordagens desse estudo para a criação do jogo pretendido.

II. Segundo momento: Consiste na aplicação do jogo que foi realizada com 5 (cinco) docentes com formação em licenciatura em Química, sendo que dois atuam na educação profissional e tecnológica, três na educação básica. Três dos professores possuem mestrado e os demais curso de especialização. Antes dos docentes testarem o jogo, explicou-se, como o jogo foi desenvolvido e como o mesmo funciona, essas etapas estão detalhadas nos tópicos seguintes e, por fim realizou-se a coleta de dados através da aplicação de um questionário, objetivando-se transparecer as opiniões dos docentes em relação ao jogo proposto. Ao apresentarmos nos resultados e discussões os nomes dos professores são codificados por uma letra maiúscula do alfabeto a fim de preservação de privacidade.

a) Desenvolvimento do Jogo

Para a construção do jogo baixou-se (download gratuito) o Scratch no computador, o qual tinha o sistema operacionalWindows 10, pois assim foi possível criar o jogo off-line. A maioria das imagens dos cenários, dos objetos e dos personagens foram adquiridas do banco de imagens do Google, sem necessidade de copyright. A imagem da planta da casa foi construída no aplicativo Sketchup, que é uma ferramenta que permite criar modelos em 3D no computador. Pesquisou-se quais objetos e alimentos que estão presentes em uma casa tradicional e tinham relação com alguma função orgânica como, 
por exemplo, o café tem a cafeína que em sua fórmula apresenta algumas funções orgânicas. Entretanto, apenas uma dessas funções foi escolhida para não confundir os alunos prejudicando a jogabilidade, no caso foi a função Amina, logo após utilizou-se uma imagem proveniente do banco de dados do google imagens relacionadas ao café para inserir no cenário mais adequado e assim foi feita para os demais.

O eixo escolhido para abordar no jogo foi química orgânica, mais especificamente sobre funções orgânicas, tendo em vista a dificuldades de memorização ou semelhanças entre os grupos funcionais. $\mathrm{O}$ processo de ensino e aprendizagem de química orgânica consiste na transmissão e recepção dos conteúdos em sala de aula, que, muitas vezes, não são assimilados pelos alunos. Pazinato (2012, p. 21) relata que "Mesmo a Química Orgânica estando intrinsecamente relacionada com a vida, a maioria dos professores do ensino médio ainda tem muitas dificuldades em contextualizar os conteúdos curriculares dessa disciplina em suas aulas".

O jogo criado foi o jogo "QUÍMICA DO LAR”, que tem por objetivo pedagógico fazer com que os alunos consigam estabelecer referência entre o conteúdo de funções orgânicas ministrados em sala de aula e sua presença em produtos domésticos do seu cotidiano.

b) Funcionamento do Jogo

O jogo Química do Lar começa com a tela que apresenta as opções aprender e desafios conforme a figura 1 .

Ao selecionar a opção “APRENDER” o usuário será direcionado para a tela das principais funções orgânicas (figura 2) onde poderá escolher qualquer uma das funções orgânica para saber como é sua nomenclatura e após observá-la na parte inferior dessa tela terá a opção "jogar”. Caso o usuário queira conhecer outra função orgânica basta clicar na palavra "MENU" que irá retornar para a tela das funções orgânicas. Caso o usuário escolha a opção "DESAFIOS" ou "JOGAR" será direcionado para a tela que demostra a planta de uma casa a qual apresenta quatro cômodos que são: a sala, um quarto, um banheiro e a cozinha (figura 3). 
Figura 1 - Tela inicial do jogo

\section{QUÍMICA DO LAR}
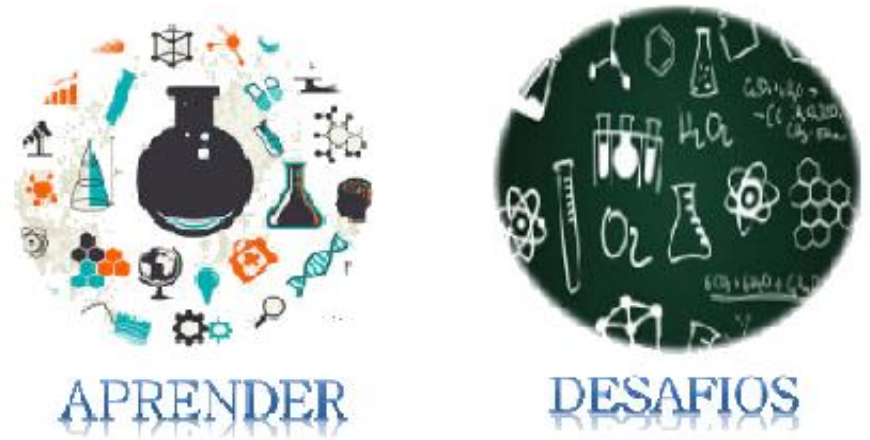

DESAFIOS

Fonte: Os autores (2019)

Figura 2- Tela do resumo das funções orgânicas

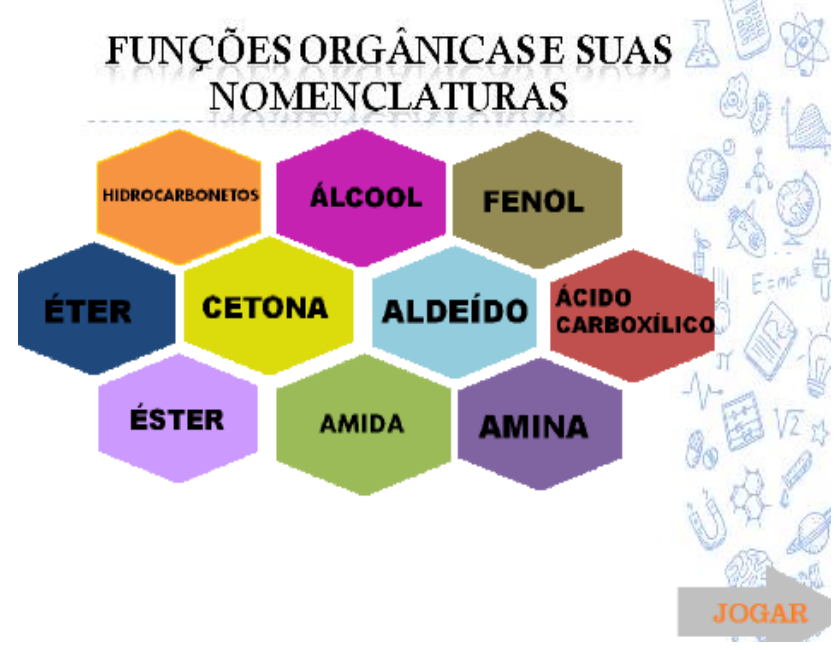

Fonte: Os autores (2019)

No momento em que surgir a tela da planta da casa (figura 3) o tempo aparecerá e começará a contagem progressiva. Ao posicionar o cursor do mouse em cima de um dos compartimentos da casa o brilho aumentará como se pode observar na (figura 3), em que o cursor está em cima do cômodo do quarto e a intensidade de luz aumentou indicando 
que em um clique inicia-se o jogo. Nessa tela o usuário pode escolher qualquer compartimento da casa para começar o jogo.

Figura 3- Tela da planta da casa
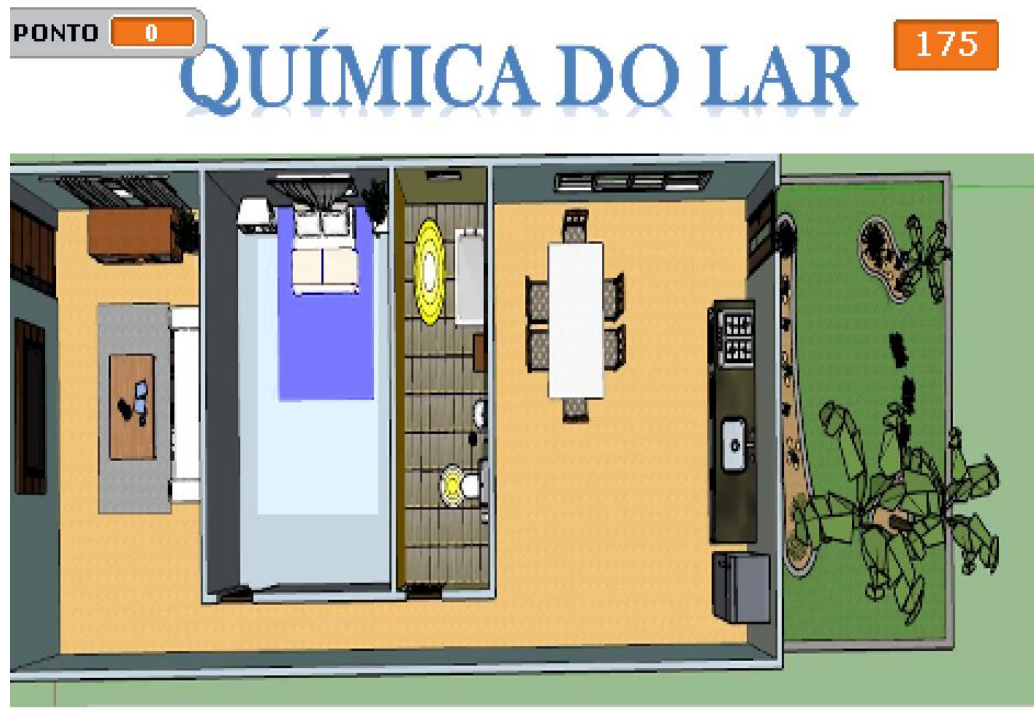

Fonte: Os autores (2019)

Por exemplo, o usuário escolheu a cozinha, ao clicar será direcionado para este compartimento onde deverá escolher um objeto que, ao clicar, aparecerá uma pergunta que envolve funções orgânicas relacionadas ao objeto escolhido. No exemplo, o usuário escolheu a xícara de café em que, ao clicar aparecerá a fórmula da cafeína e perguntará qual é a função orgânica que está destacada na cor vermelha na fórmula da cafeína. $O$ usuário então terá duas alternativas de respostas, se o usuário acertar a resposta ganhará um ponto e se errar diminuíra um ponto. Quando o usuário responder todas as perguntas solicitadas naquele ambiente aparecerá a opção para prosseguir que ao clicar será direcionado para a planta da casa mostrando em qual ambiente já foi solucionado e quais ainda faltam jogar.

O usuário só pode escolher para jogar em ambientes que ainda não jogou. Caso o usuário queira jogar novamente naquele ambiente, não será possível, ao menos que reinicie o jogo. Somente quando aparecer a tela da planta da casa indicando que todos os ambientes já foram jogados aparecerá à opção "avançar" que ao clicar irá para a tela 
indicando que o aluno concluiu o jogo. Nessa tela aparecerá a pontuação e o tempo do jogo. O jogo pode ser acessado no link: https://scratch.mit.edu/projects/324530322.

\section{RESULTADOS E DISCUSSÕES}

Os resultados e discussões foram baseados na análise do questionário que os docentes responderam, o qual teve por objetivo avaliar o grau de aceitação do jogo, ou o que ele ainda precisa melhorar para ser um bom recurso para o ensino de química, e também nesse questionário havia perguntas referentes aos jogos digitais a fim de saber qual importância os docentes atribuem a essa ferramenta.

Ao indagar sobre o grau de dificuldade de ensinar funções orgânicas. De acordo com o gráfico $1,80 \%$ dos professores apresentam pouca dificuldade em ministrar o assunto de funções orgânicas e $20 \%$ não apresenta nenhuma dificuldade.

Gráfico 1: Dificuldades dos docentes em trabalhar o conteúdo de química orgânica.

\section{1-"Você apresenta alguma dificuldade em trabalhar o conteúdo de química orgânica?"}

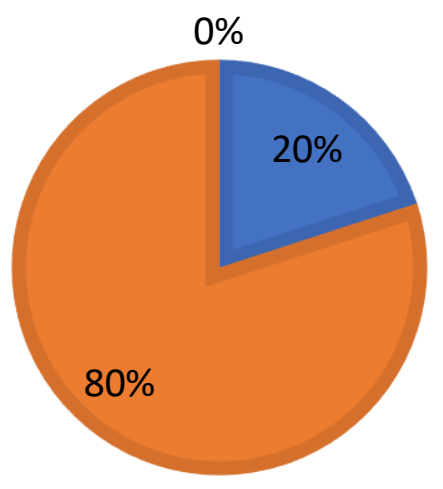

Nenhuma dificuldade

Pouca Dificuldade

Muita dificuldade

Fonte: Os autores (2019). 
No entanto, ao responder à pergunta que se referia ao grau de dificuldade dos seus alunos aprenderem tal assunto, todos afirmaram que seus alunos apresentam dificuldades em aprender a temática envolvida, pois o conteúdo exige um grau de compreensão maior pelo fato dele apresentar muitas fórmulas, talvez por esse motivo muitos dos discentes não consigam relacionar o conteúdo com o seu dia a dia o que dificulta a sua aprendizagem.

Nesse sentido, Pereira (2013) aborda que a maior dificuldade que o docente encontra em sala de aula é fazer com que os alunos sejam capazes de relacionar os conceitos vistos em sala de aula com o seu cotidiano, portanto, é de fundamental importância o desenvolvimento de novas metodologias de ensino, que insiram práticas alternativas e complementares aos métodos tradicionais, se possível utilizando meios tecnológicos, como o proposto nesta pesquisa.

Ao questionar se os docentes consideram que os jogos digitais auxiliam para o processo de ensino aprendizagem, a partir das respostas pode-se concluir que todos reconhecem a importância que os jogos digitais têm para o processo de ensino aprendizagem, assim como a deficiência causada pela falta das tecnologias no sistema educacional dificulta a aprendizagem dos alunos, pois em muitos conteúdos de química, o método tradicional não é suficiente, uma vez que alguns fenômenos químicos são abstratos e necessita que o professor ajude o aluno a visualizar, associar e compreender esses fenômenos (SANTOS, 2012). Uma boa maneira de minimizar essa situação é utilizar recursos tecnológicos (VEIGA; QUENENHENN; CARGNIN, 2012).

Segundo Ramos, Silva e Paiva (2015) a importância de o professor adquirir habilidades e técnicas referentes às tecnologias, deve-se ao fato de que esses meios estão mais contextualizados com a realidade em que o aluno de hoje vive e, com certeza, vai ser um fator de motivação a mais para despertar o interesse do educando. "Para que o processo ensino-aprendizagem seja mais dinâmico e atraente é necessário que o professor se adapte aos novos contextos vivenciados, permeados por novas tecnologias". (MELO J; MELO A; MELO J. N, 2014, p.15).

Questionou-se se os docentes já utilizaram ou fazem uso dos jogos digitais, as respostas podem ser vistas no gráfico 2. Nele pode-se observar que $80 \%$ dos professores 
afirmam que utilizam ou já fizeram uso dos jogos digitais em suas aulas e $20 \%$ afirmam que não fizeram uso da ferramenta.

Gráfico 2 - Uso dos jogos digitais em sala de aula

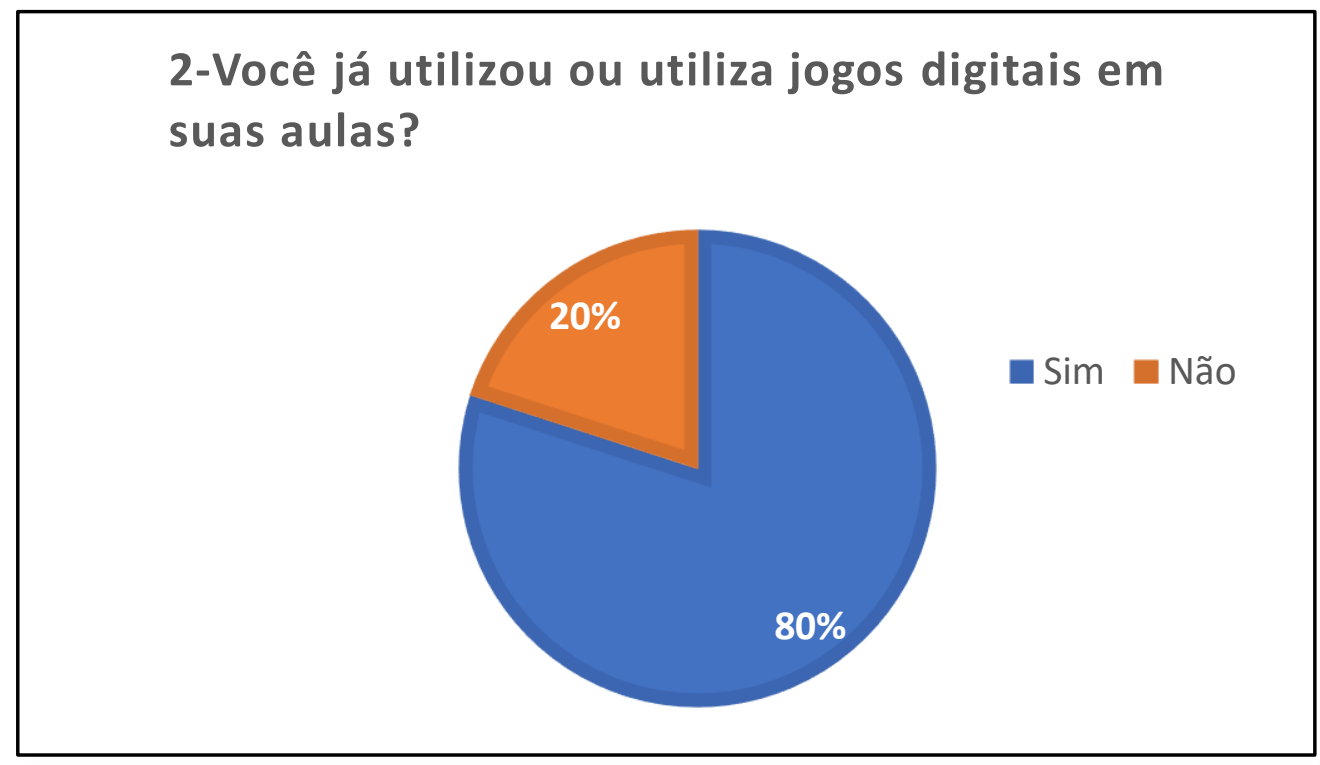

Fonte: Os autores (2019).

O uso de jogos digitais no ensino de química tem sido tema de estudos e pesquisas de vários autores, destacando a eficiência em despertar atenção nos alunos. Tal interesse advém da diversão que, muitas vezes, produz efeito positivo no aspecto disciplinar.

Sabe-se que os jogos digitais são recursos tecnológicos e que por si só não causará efeitos positivos no processo de ensino aprendizagem, pois é necessária a presença de um educador para que o mesmo possa ser utilizado para fins educativos. $\mathrm{O}$ gráfico 3 , mostra as respostas para o seguinte questionamento "quais são as maiores dificuldades em utilizar jogos digitais em sala de aula?"

É possível analisar no gráfico que $90 \%$ dos professores tem muita dificuldade pelo fato de não encontrarem jogos que abordem o conteúdo dentro da realidade do aluno e $10 \%$ por não possuir recursos. 
Gráfico 3 - Principais dificuldades dos docentes em utilizar jogos digitais em suas aulas

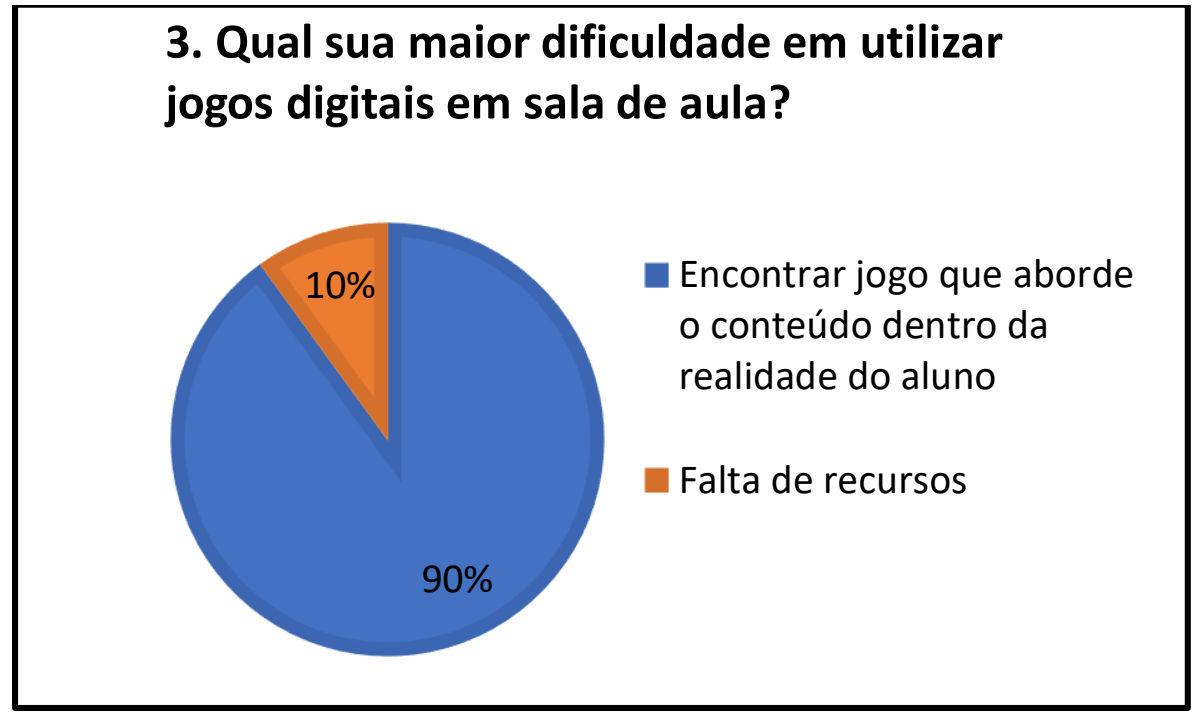

Fonte: Os autores (2019).

Muitos dos docentes não usam os jogos digitais em suas aulas devido a falta de recursos tecnológicos, pois em muitas escolas ainda não possuem aparatos tecnológicos como, por exemplo, um laboratório de informática e, quando a escola possui, muitas vezes os professores não têm apoio dos membros da escola para realizar uma aula mais atrativa e dinâmica. Existe também o receio entre professores de que os alunos não vão querer participar, cooperar e interagir ou que as atividades com computadores exponham suas vulnerabilidades tecnológicas em relação ao conhecimento dos alunos que atualmente entendem mais de informática do que os docentes (LEMOS, 2016).

Para verificar se o jogo Química do Lar poderá contribuir para o ensino de Química, foi feito a seguinte pergunta "O que você achou do jogo Química no lar para ensinar Química orgânica?”. O Gráfico 4, ilustra as respostas adquiridas: 
Gráfico 4 - Resultado do que os docentes acharam do jogo proposto

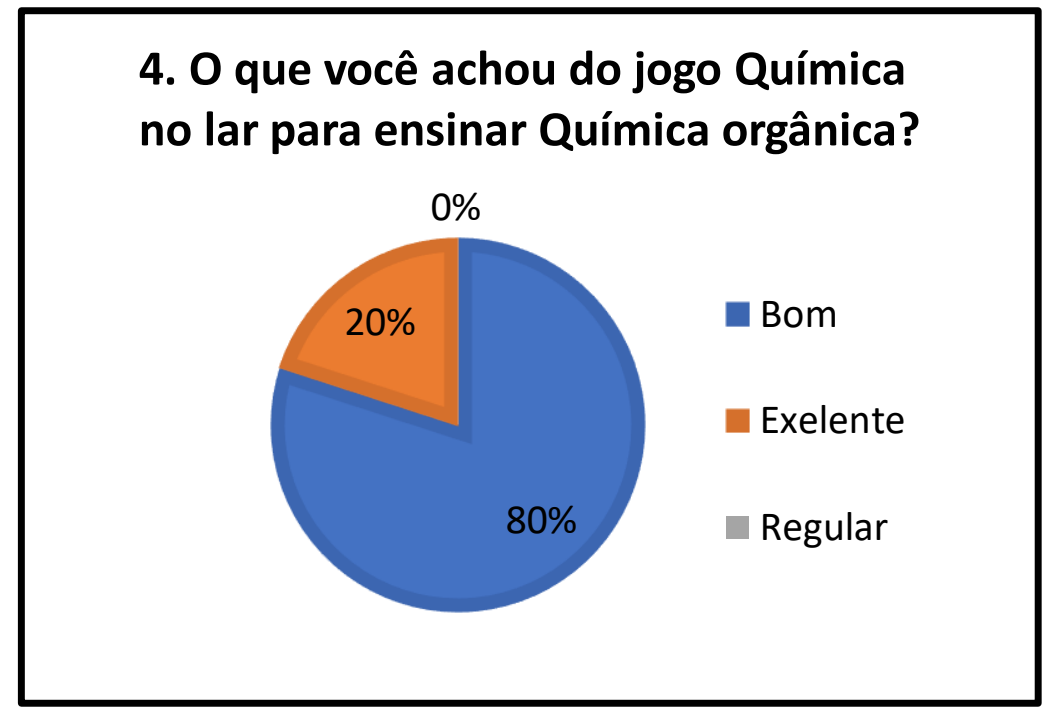

Fonte: Os autores (2019).

Mediante a leitura do gráfico é perceptível que $80 \%$ dos professores afirmaram que o jogo apresentado é bom, e $20 \%$ afirmam que é excelente. Sobre essa perspectiva o jogo foi aprovado perante os educadores e todos disseram que utilizariam em suas aulas. Este resultado propõe que o jogo Química do Lar poderá auxiliar os professores de química em suas aulas tornando-as mais dinâmicas e atrativas.

Com o intuito de saber quais as críticas dos docentes em relação ao jogo químicas no lar, perguntou-se: Qual sua opinião sobre o jogo Química no lar? Algumas opiniões relataram a importância de os jogos digitais poderem ser usados off-line, como se pode observar nos comentários abaixo.

No atual Cenário que o ensino está no Brasil, principalmente em relação às novas tecnologias educacionais, esse jogo se sobressai, pois, ele abrange o conteúdo de química orgânica de uma maneira simples e que vai chamar a atenção dos discentes sem dúvidas. Um ponto importante e que o jogo roda online e off-line, isso pode facilitar a sua implantação nas escolas que não possuem acesso a interne (professor A). 
Maravilhoso, é off-line o que possibilita ser utilizado em escolas que não possuem internet, assim como traz objetos e alimentos do cotidiano do aluno, fortalecendo a contextualização e encurtando a distância para o que o aluno aprenda com o que ele vive. (Professor B).

Além de elogiarem aspectos do jogo, também deram algumas sugestões para aprimorar o jogo. Veja abaixo alguns comentários.

"Seria interessante se o tempo no jogo fosse crescente e não decrescente, pois assim o professor poderia verificar em qual tempo o aluno consegui terminar o jogo" (professor A).

“O jogo química no lar pode ser uma excelente alternativa para a aprendizagem de química orgânica. Acredito que os compostos mais complexos deveriam apresentar uma pontuação maior para estimular ainda mais o aprendizado do aluno". (Professor B).

"Acho que ficaria bom realçar os objetos quando o mouse é colocado em cima. No resumo seria interessante trazer aspectos históricos da química orgânica”. (Professor C)

Essa avaliação foi bastante importante, pois através dela pode-se aperfeiçoar o jogo e seguir para o próximo passo pretendido que é aplicar com os discentes e posteriormente disponibilizar o jogo para os demais professores fazerem o uso dessa ferramenta. 


\section{CONSIDERAÇÕES FINAIS}

A disciplina de Química necessita ter um educador dinamizador do processo de ensino, o qual deve buscar alternativas metodológicas diferenciadas para que ocorra a aprendizagem. Desse modo, o jogo digital configura-se como uma alternativa para que os discentes entendam e memorizem novos conhecimentos e estabeleçam relações com conteúdos que aprenderam de forma ativa, dialogada e autônoma com seu dia a dia.

O jogo produzido no presente trabalho foi aprovado perante os professores, o qual tem como intuito auxiliar docentes da área de Química por meio da plataforma Scratch que é uma ferramenta que tem várias funcionalidades podendo ser usada para criar histórias interativas, animações e jogos, professores de qualquer disciplina podem criar novas metodologias para ensinar, com atividades que irão despertar o interesse pelos conteúdos abordados e desse modo contribuindo para o processo de ensino aprendizagem.

Os docentes investigados ressaltaram a importância dos jogos para o sistema educacional principalmente os jogos off-line que serviram como uma ferramenta alternativa para ser utilizado em escolas que não possuem internet. Essa ferramenta tecnológica pode ser amplamente utilizada para enriquecer as aulas de química, proporcionando grandes vantagens se comparado às aulas tradicionais. Recomenda-se a criação de recursos tecnológicos como o Jogo Química do Lar, pois assim as aulas serão mais dinâmicas e inteligíveis, levando aos alunos um pouco da tecnologia que muitas vezes eles não encontram na escola. Portanto, a união de jogos com os conteúdos de Química, como uma nova estratégia de ensino, poderá ser um caminho para um melhor desempenho escolar.

\section{REFERÊNCIAS}

CABRAL, Ronaldo Vieira. O ensino de matemática e a informática: uso do Scratch como ferramenta para o ensino e aprendizagem da geometria. PR. 2015. 118f. Dissertação 
(Mestrado em Ciências da Educação e Multidisciplinaridade na Área de Educação). Faculdade do Norte do Paraná-FACNORT. Curitiba, PR: FACNORT, 2015.

GOMES, Susana dos Santos. Didática, Práticas Docentes e o Uso das Tecnologias no Ensino Superior: Saberes em Construção. In: REUNIÃO NACIONAL DA ANPED, 37., 2015, Florianópolis. Anais online. Florianópolis: ANPED, 2015. Disponível em www.anped.org.br/sites/default/files/trabalho-gt04-3905.pdf. Acesso em 20 de agosto de 2018.

GERHARDT, Tatiana Engel; SILVEIRA, Denise Tolfo (orgs). Métodos de pesquisa. Porto Alegre: Editora da UFRGS, 2009. Disponível em ttp://www.ufrgs.br/cursopgdr/downloadsSerie/derad005.pdf . Acesso em 20/05/2019.

KLEINUBING, Jorge José. Utilizando o Scratch para o ensino da Matemática. 2016. 69 f. Trabalho de Conclusão de Curso (Graduação em Licenciatura em Informática). Universidade Tecnológica Federal do Paraná - Campus Francisco Beltrão. Curitiba, PR: UTFPR, 2016.

LEMOS, Regiane de Fátima Franzoi. O uso dos Jogos Digitais como Atividades Didáticas no $2^{\circ}$ ano do Ensino Fundamental. 2016. 26f, Monografia (Curso de Especialização em Educação na Cultura Digital) - Universidade Federal de Santa Catarina - UFSC. Biguaçu: UFSC, 2016.

MEDEIROS, Ana Clara Santos de. O uso das novas tecnologias no ensino de química: Um estudo de caso sobre as potencialidades dos jogos digitais. PB. 2014. 32f. Monografia (Curso de Especialização em fundamentos da educação: Práticas Pedagógicas interdisciplinares). Universidade Estadual de Paraíba. Católe do Rocha: UEPB, 2014.

MELO, Jefferson Ricardo do Amaral; MELO, Adriana Martins de Araujo; MELO, Jessika Nayara do Amaral. Novas Tecnologias no Ensino Superior: um estudo ibliométrico sobre sua produção científica. Revista educação e tecnologia. [Online]. Curitiba. n. 13, p.1-16. 2015. Disponível no site. revistas.utfpr.edu.br

NASCIMENTO, F.G.M; COSTA, T.R. O uso do SCRATCH no ensino de química. SIMPÓSIO BRASILEIRO DE EDUCAÇÃO QUÍMICA-SIMPEQUI, 13., 2015. Anais... 
Fortaleza:

$\mathrm{ABQ}$,

2015.

Disponível

em:

http://www.abq.org.br/simpequi/2015/trabalhos/90/6486-12833.html,

acesso

em: 05/08/2019.

PAZINATO, S. M. et al. Uma Abordagem Diferenciada para o Ensino de Funções Orgânicas através da Temática Medicamentos. Revista Química Nova na Escola. São Paulo, v. 34, n. 1, p.21-25, 2012.

PEREIRA, Daiane; GERSTBERGER, A. Juliana. O ensino da química experimental com materiais alternativos. 2013. 55 f. Trabalho de Conclusão de Curso - Curso Superior de Química - Bacharelado em Química Industrial/Licenciatura em Química, Universidade Tecnológica Federal do Paraná (UTFPR). Pato Branco: UTFPR, 2013.

PORTZ, Luciano G.; EICHLER, Marcelo L. Uso de jogos digitais no ensino de química: um super trunfo sobre a tabela periódica. Debates sobre o Ensino de Química, [S.1.], out. 2013. ISSN 2318-8316. Disponível em: 〈https://publicacoeseventos.unijui.edu.br/index.php/edeq/article/view/2786>. Acesso em: 06 set. 2019.

RAMOS, Marcos Roberto; SILVA, Gildene do Ouro Lopes; PAIVA, Andressa Jackeline de Oliveira Mario. Tecnologia no Ensino Superior na Percepção do Docente.Acta Cient. São Paulo, v22, n.2, p .10-24, 2013.

SANTOS, J. M. et al. Jogos didáticos no processo de ensino aprendizagem de química. In: ENCONTRO NACIONAL DE EDUCAÇÃO, CIÊNCIA E TECNOLOGIA, 1., 2012, Campina Grande. Anais eletrônicos... Campina Grande: UEPB, 2012. Disponível em http://www.if.ufrgs.br/eenci/artigos/Artigo_ID45/v2_n3_a2007.pdf. Acesso em: 20 de agosto de 2019.

SILVA et al. Novas Tecnologias Educacionais: Explorando o tema ar, água e solo tendo o Scratch como ferramenta pedagógica no nível fundamental. Revista Sciente Plena. Sergipe, n. 12, n. 6, p. 1-9, 2016.

SILVA FILHO, Supercil Mendes da. Desenvolvimento de jogos digitais por alunos do ensino médio para o desenvolvimento de conceitos químicos. 2015. 90 f. Dissertação 
(Mestrado em Química). Universidade Federal de Goiás. Instituto de Química (IQ). Goiânia: UFG, 2015.

THIOLlENT, M. Metodologia da Pesquisa-ação. São Paulo: Cortez Editora, 1947.

TRIMBLE NAVEGATION. Sketch Up.2017. Disponível em: https://www.sketchup.com/pt-BR>. Acesso em 02 de julho de 2019.

WEBBER et al. Reflexões sobre o Software Scratch no Ensino de Ciências e Matemática. Revista Renote Novas Tecnologias na Educação. v. 14, n 2, p. 1-10, 2016. 


\section{APÊNDICE A - QUESTIONÁRIO APLICADO AOS DOCENTES}

\section{NOME:}

\section{FORMAÇÃO:}

\section{INSTITUIÇÃO ONDE TRABALHA:}

\section{TEMPO DE DOCÊNCIA:}

1. Você apresenta alguma dificuldade em trabalhar o conteúdo de química orgânica?
( ) Muita
( ) Pouca
( ) Nenhuma

2. Seus alunos apresentam dificuldade em compreender esse conteúdo?
( ) Muita
( ) Pouca
( ) Nenhuma

3. Você considera que os jogos digitais ajudam no processo de ensino aprendizagem.
( ) $\operatorname{Sim}$
( ) não

4. Você já utilizou ou utiliza jogos digitais em suas aulas?
( ) $\operatorname{Sim}$
( ) Não

5. Qual sua maior dificuldade em utilizar jogos digitais em sala de aula.

( ) Encontrar jogo grátis.

( ) Encontrar jogo que aborde o conteúdo dentro da realidade do aluno

( ) Não possuo dificuldade em utilizar jogos

Outros

6. O que você achou do jogo Química no lar para ensinar Química orgânica?

( ) Excelente ( ) Bom ( ) Regular

7.Você sentiu dificuldade para compreender e jogar? 
( ) Sim ( ) Não ( ) Um pouco

8. Você utilizaria esse jogo em sua aula em suas aulas?

( ) $\operatorname{Sim}$ ( ) Não

9. Qual sua opinião sobre o jogo Química no lar?

10. Você conhece outras ferramentas para o ensino de química? Se sim, quais? 